\title{
APROXIMACIÓN AL SENTIDO DE LOS TATUAJES EN EL MALESTAR EN LA CULTURA
}

Sandra Serrana Vidal Viera Licenciada en Psicología de la UDELAR Especialista en Psicoterapia Psicoanalítica del IUPA Magíster en Psicoterapia Psicoanalítica del IUPA Miembro de AUDEPP

Correo electrónico: lic.sandra.vidal@gmail.com ORCID: 0000-0002-7372-2990 


\section{Resumen}

Este artículo está basado en la tesis de Maestría en Psicoterapia Psicoanalítica, cohorte 2016, del Instituto Universitario de Posgrado (IUPA) de la Asociación Uruguaya de Psicoterapia Psicoanalítica (AUDEPP). Reflexiona sobre aspectos del desarrollo de la investigación y sus aportes para la psicoterapia psicoanalítica.

La investigación, con metodología cualitativa, se centró en explorar la percepción del significado que tiene para los/las jóvenes el tatuaje y la posible vinculación o no con cambios en su psiquismo. El análisis de contenido de las entrevistas semiestructuradas se realizó desde el marco teórico del psicoanálisis para comprender la construcción de sentido que los/las jóvenes le dan al tatuaje, orientado hacia el posible cambio psíquico.

De los antecedentes de investigación surgen las preguntas y a partir del análisis de las entrevistas realizadas se delimitan cuatro aspectos centrales a abordar: la piel, la subjetividad, el dolor-duelo y el cambio psíquico.

En el proceso de investigación se profundizaron conceptos y surgieron nuevas interrogantes y posibles líneas de investigación en referencia al tema elegido.

Palabras clave: tatuaje, cambio psíquico, jóvenes.

\section{An Approximation to the Meaning of Tattoos in Culture Discontent Abstract}

This article is based on a master's thesis in psychoanalytic psychotherapy from the Postgraduate Institute (IUPA) of the Uruguayan Association of Psychoanalytic Psychotherapy (AUDEPP). It reflects on aspects of research development and contributions to psychoanalytic psychotherapy.

The research with qualitative methodology, focused on exploring the perception of the meaning of tattoos for young people and the possible link or not, to changes in their psyche. The content analysis of the semi-structured interviews was carried out from the theoretical framework of psychoanalysis in order to understand the construction of meaning that young people give to tattoos, oriented towards possible psychic change.

From the research background questions arise, and from the analysis of the interviews carried out, four central aspects to be addressed are defined: skin, subjectivity, grief-pain and psychic change.

In the research process concepts were examined, and new questions and possible lines of research emerged in reference to the chosen topic.

Keywords: tattoo, psychic change, youth. 
— ¿Por qué lo ubicaste ahí?

—Para verlo, para estar..., que estuviera visible.

Entrevistada N. ${ }^{\circ}$ 3, 19 años.

\section{INTRODUCCIÓN}

El tema de la investigación fue promovido a partir de la experiencia clínica de colegas y propia. Se buscó problematizar o producir conocimientos de valor científico que sirvieran como instrumentos para el abordaje clínico cuando el tatuaje ya está presente como un hecho consumado o para abordarlo previo a su concreción

Durante el proceso de investigación se utilizó la entrevista semiestructurada, en su mayoría realizadas en consultorio. La primera entrevista con el consultante es reveladora de las vivencias, de los sentimientos, y enuncia de alguna manera la conflictiva. En la investigación fue utilizada esta herramienta de manera tal que las condiciones de entrevista remitieron a un encuadre similar al utilizado en la psicoterapia psicoanalítica, lo que permitió, en este caso, sostener la asimetría entre quien entrevista y quien es entrevistada/o, la empatía necesaria para entablar la comunicación con el otro/a, el tiempo acordado, el espacio, las condiciones de privacidad del consultorio y el acuerdo de proteger los datos personales en todos los detalles. El entorno cálido y contenedor habilitó el despliegue del mundo interno e histórico del entrevistado/a. Cabe señalar la importancia destacada de esta herramienta para la investigación cualitativa (la primera entrevista en la clínica). 


\section{LA PIEL Y LA POSMODERNIDAD}

En las entrevistas surgieron variadísimos temas, inabarcables, que serían pasibles de investigación; pero hubo que recortar la información, definir qué contenidos integrar y cuáles no. Uno de los temas más recurrentes fue el de la piel denominada lienzo (como el soporte de la pintura que realizará el artista), donde quien se tatúa diseña la historia personal que desea o elige para ser tatuada.

A medida que se iban sucediendo las entrevistas, surgían nuevas interrogantes, como, por ejemplo: ¿cómo la piel se va transformando en lienzo para algunos de los consumidores/as de tatuajes? Es inevitable pensar en cómo los reality show, los juegos online, el cine, los videos, las redes sociales, la prensa escrita, la radio, la televisión, los informativos, etcétera, inciden en la transformación conceptual de amplísimos temas, que podemos comprender desde la perspectiva de McLuhan y Powers (1995). Estos autores proponen que los medios de comunicación mundiales se transforman rápidamente, así como se transforma la vida, se intensifican aspectos y al mismo tiempo se vuelven obsoletos otros, sufren modificaciones continuas. En este último siglo, los medios de comunicación han incidido en los hábitos y opiniones del público, y hasta en las modificaciones del pensamiento humano, porque —según McLuhan y Powers (1995) — los medios de comunicación y las tecnologías poseen una estructura fundamentalmente lingüística, son lenguaje que se extiende a través de los sentidos.

En los escritos de Freud (1994b), los cambios incesantes de la civilización posibilitada por las restricciones impuestas desde la cultura y las contrapuestas pulsiones humanas generan malestar. Podemos pensar la piel como lienzo, como mediador propuesto desde los medios de comunicación, donde se expresan malestares imborrables, una protesta más ante la imposición del principio de realidad sobre el principio de placer. 
También podríamos interpretar que, para algunas personas, el tatuaje en el lienzo les dio sentido a su ser, conformó sus psiquismos y brindó una nueva envoltura psíquica a cada una/o, capturando momentos de sus vidas como si fuera una fotografía que se presentifica en el Yo-piel (Anzieu, 1987). Serían etapas o situaciones pasadas que se registran para mantenérselas presentes, vívidas, para no olvidarlas: «que no sea efímero, que no sea como la palabra, cada vez que lo vea, lo recuerde, sí, es así, esto es propio» (Entrevistada N. ${ }^{\circ} 1,25$ años).

Por otra parte, cabe preguntar: ¿por qué algunas/os de las/os entrevistadas/os necesitan mantener presente su historia en la piel?

... el tatuaje que te lo vas a llevar siempre contigo, hay forma de sacarte un tatuaje, por supuesto, hay tratamientos, te los puedes sacar, pero es una forma más perpetua de llevarlo, y de sentirlo propio, tuyo, que sea tan literal que lo lleves en la piel, no creo que haya otra forma, [...] van a estar conmigo es una forma de estar acompañada, los llevo siempre sobre mí. (Entrevistada N. ${ }^{\circ}$, 24 años)

En el proceso de entrevistas parecía que nos introducíamos en un mundo diferente, no se comprendía la necesidad imperiosa de presentificar hechos, personas o fechas de la historia personal por medio del tatuaje. Posteriormente, entre lecturas y discusiones se fue vislumbrando que sería un modo de detener el paso del tiempo y el olvido, lo cual habilitaría la fantasía de eternidad y juventud, aquello que el principio de realidad destruye. Desde esta perspectiva, Lipovetsky (2006) ha analizado la sociedad posmoderna del siglo xx en cuestiones como la cultura de masas, la moda, el consumismo, el hedonismo, el narcisismo apático y otros temas que aluden a fenómenos sociales y culturales, que incluyen a las vivencias de tatuarse como la posibilidad de adquirir la eterna juventud. 
... porque hay muchos tatuajes que, si te ponés a preguntar, no tienen significado como tienen los míos, porque son lindos, porque ves una imagen en internet que se te antojó, un león y se hace un león. (Entrevistada N. ${ }^{\circ}$, 24 años)

El gusto por lo estético no tradicional y la adquisición inmediata del tatuaje como objeto de gratificación adquiere sentido cuando algunas de las entrevistadas/os expresan que tatuadas/os mantienen presente a personas o situaciones pasadas a modo de fotografía reveladas en la piel. Este concepto de fotografía resultó novedoso: la foto sale del álbum y del celular para instalarse en la piel.

El tatuaje les produce el placer efímero y prontamente requiere de una nueva gratificación, porque no es suficiente. A modo de ejemplo, para justificar sus tatuajes y la presentificación que implican, una de las entrevistadas dice: «¿Cómo confío yo en un recuerdo?» (Entrevistada N. ${ }^{\circ}$ 6, 25 años).

\section{CAMBIO PSIQQUICO}

Desde otra perspectiva, se puede pensar que los efectos del tatuaje en el psiquismo dependerían de la realidad psíquica del sujeto. Es decir que, en la instancia de realización del tatuaje, el individuo presentificaría lo que aún no puede simbolizar en la etapa que transita. Pero, con el paso del tiempo, esa presentificación podría producir el acompañamiento del cambio psíquico o el acompañamiento en la tramitación de duelos. Como sugiere Reisfeld (2004): «el tatuaje adquiere la connotación de un necesario operador psíquico que posibilita un tramo de la simbolización» (p. 120). En otras palabras, a partir de realizarse el tatuaje, y sobre todo con el transcurso del tiempo, se construye una nueva cadena de significaciones. 
Este aspecto puede percibirse cuando las entrevistadas/os recuerdan la etapa en que se tatuaron:

... me lo voy a tatuar para tener una visualización constante en mi cuerpo, lo veo, me lo tatué por algo, es porque pasé una historia y ahora es diferente, quiero crearme, por eso me lo tatué, me lo tatué con mi letra porque no encontraba una letra que me gustara, quiero que sea especial, que sea único. (Entrevistada N. ${ }^{\circ}$ 6, 25 años)

Recordar lo vivido y elaborarlo a través de la representación en la piel nos acerca a Winnicott (1965) y a pensar en la falta o la falla del rol de sostén, en la necesaria disposición de un otro en etapas tempranas. Estas situaciones probablemente promueven montos de angustias desbordantes, que con la concreción del tatuaje se contendrían y delimitarían, se transformarían en defensas, construirían nuevas significaciones.

\section{PENSAMIENTO MÁGICO}

En el discurso de algunas/os entrevistadas/os se percibe que el tatuaje adquiere connotaciones similares a las propias de etapas arcaicas de la humanidad, en las que a su portador le proveía un poder especial ante el dolor, el enemigo o la muerte, dentro de una concepción animista del mundo, ${ }^{1}$ ligada al pensamiento mágico. Como expresa Freud (1994b) respecto del hombre primitivo: "Cuando le ha sucedido una desgracia no se achaca la culpa a sí mismo, sino al fetiche, que evidentemente no ha cumplido su cometido» (p. 3055). Este autor analiza la diferencia entre el hombre de la cultura occidental y el hombre primitivo en el sentido de

1 Animismo en el sentido antropológico que le dio Edwar Taylor en el siglo xIX. 
que el primero vive la culpa achacándose a sí mismo, porque la incidencia de la religión, la familia y el Estado contribuía a transformar las pulsiones sexuales agresivas en sentimiento de culpa, limitaba así las pulsiones agresivas y contribuía a la formación de la cultura.

El pensamiento mágico, así como posibilita la fantasía y conlleva la creatividad, también aporta a la capacidad de desarrollar explicaciones acerca de lo que no se entiende o no se puede conocer. Por ejemplo, la fantasía de que todo dure para siempre, «congelar ciertos momentos» (Entrevistada N. ${ }^{\circ}$ 5, 23 años), es negar el paso del tiempo y la finalización de la vida. Otra fantasía es que el tatuaje, como objeto protector, hará las veces de amparo o resguardo ante las adversidades de la vida: «en la primera semana perdí el collar y dije: “¿Y sí es verdad lo que dicen?” [...], ahora me van a robar [...], me lo quise tatuar» (Entrevistada N. ${ }^{\circ}$ 11, 20 años).

Como en el pensamiento animista del niño del que habla el constructivismo piagetiano, que le sirve para dar coherencia a sus razonamientos sobre situaciones, deseos o emociones (Piaget, 1991), encontramos en estas expresiones de las entrevistadas/os hipótesis especulativas acerca de lo que acontecerá como efecto cuasi mágico. La idea de objeto protector ante el cambio que significa dejar la familia y a veces el entorno es entendible desde la perspectiva de mantener algo de lo perdido, aferrarse a objetos o tatuajes en medio de la situación caótica de cambio.

\section{DUELO Y TATUAJE}

A través de lo expresado por las/os entrevistadas/os, se percibe que en ciertos casos el tatuaje también parecería contribuir al trabajo de duelo ante diferentes pérdidas. Históricamente, en algunas culturas como la maorí el tatuaje tenía una función específica ante las pérdidas o ante el pasaje a la adultez, formaba parte de las prácticas culturales y sociales, 
y venía inmerso en la manera como el grupo sociocultural procesaba los cambios a través de rituales. También Freud (1994b) rescata la facilitación de procesos de cambios en sociedades primitivas a través de rituales de iniciación.

En la cultura occidental los procesos son diferentes. Con el tatuaje tal vez no se llegue a una elaboración psíquica similar a lo descrito para la cultura maorí, aunque la incorporación concreta del ser querido en la piel, que lo mantiene presente permanentemente, establece una relación diferente con quien ya no está, como dice Allouch (1996).

De acuerdo a las diferencias culturales y sociales, surge la pregunta: ¿cuánto del cambio en los sentidos y usos sociales del tatuaje incide en el efecto psíquico que producen?

Otra manera de entender estas prácticas es a través de lo que Freud (1997c) describe como «el duelo intenso [...], el apartamiento de toda función no relacionada con la memoria del ser querido» (p. 2092). El tatuaje mantendría concretizado este aspecto del duelo, lo que podría detener la elaboración de sus siguientes etapas, ya que el tatuaje conlleva la condición de ser imborrable por definición, aunque en realidad se pueda borrar con láser o tatuando otro encima.

Otra manera de pensar el duelo es que se puede tramitar a través de los dispositivos del arte, como la pintura o la música. Si el tatuaje es un arte por lo creativo de la acción, entonces el tatuaje, en tanto arte, sería un recurso para tramitar un duelo. Como dice Allouch (1996), en las pérdidas hay que cambiar la relación con lo que ya no está, entonces: ¿el tatuaje podría ser un medio para lograr ese cambio?

Retomando el concepto de Reisfeld (2004) del tatuaje como operador psíquico, se puede ver que para varias entrevistadas/os el tatuaje adquiere un valor especial cuando está directamente vinculado a la ausencia de abuelas/los. En esos casos, el significado del tatuaje queda ligado a la presentificación de la abuela/o para resolver el temor al olvido: 
... y el otro [tatuaje] es la firma de mi abuela, que mi abuela falleció en abril, y nada, la quiero un montón y la extraño pila. (Entrevistada N. ${ }^{\circ} 1$, 25 años)

... y la fecha de nacimiento de mi abuela, que aún sigue viva... (Entrevistada N. ${ }^{\circ} 2,23$ años)

... tengo planes de tatuajes. Una de ella es mi abuela, un retrato de mi abuela... (Entrevistada N. ${ }^{\circ}$ 3, 19 años)

Este que es $x$ [animal mitológico], me gusta, hoy por hoy estoy tratando con mi terapeuta un tema de un duelo, porque falleció mi abuelo... (Entrevistada N. ${ }^{\circ}$ 5, 23 años)

Tatuaje de una $x$ [planta] [...], que tienen significados las $x$ [...]. La $x$ me encanta, me da mucha paz, mucha tranquilidad, mis abuelos tenían una $x$ en su casa y eso que me lleva a esta situación. (Entrevistada N. ${ }^{\circ}$ 6, 25 años)

Después me hice las fechas del nacimiento de mi madre, por supuesto, y la fecha de nacimiento de mi abuela paterna, esto fue en parte porque con mi abuela [...], mi abuela falleció hace tres años, siempre tuve una re linda relación... (Entrevistada N. ${ }^{\circ}$ 7, 24 años)

\section{CONSTRUCCIÓN DE LA SUBJETIVIDAD}

El Yo-piel y la inscripción de huellas táctiles tempranas son sostenidas y fortalecidas por el vínculo materno a modo de envoltura psíquica (Anzieu, 1987); más tarde facilitará, entre otras cosas, el desarrollo de la pertenencia 
a un grupo social a través de la ropa, el maquillaje, el tatuaje, etcétera. El grupo social al que pertenece un individuo está compuesto por el grupo de pares, el cual provee contención, identidad, sostén. La pertenencia (sentirse parte de algo) está dada por compartir intereses, ideologías o actividades imitativas, que incluyen la práctica del tatuaje y la experimentación del dolor. El grupo de pares de las entrevistadas/os está presente en comentarios que reflejan la pertenencia antes mencionada. Entonces, la percepción del efecto del tatuaje en la psiquis se inclinaría hacia la integración del psiquismo en relación a lo subjetivo y a lo intersubjetivo. ${ }^{2}$

... me lo hice con mis hermanos a este tatuaje, o sea que los $x$ [número de hermanos] tenemos el mismo tatuaje, y lo veníamos hablando hace tiempo, hace como un año, en realidad estaban esperando que yo cumpliera los 18, pero no, no esperaron [risas]. Hace como un año ya, nos tatuamos al mismo tiempo. [...] en la camilla mis hermanos me sacaban fotos y le mandaban a mi madre y le decían que me había desmayado... No, ellos pusieron música [...] no sé, es como que siempre está ese lazo entre los hermanos, por ejemplo, ahora mi hermano se va a ir a estudiar a $X$ [ciudad] y no sé, como que queda eso, como una conexión, no sé cómo decirlo, como que queda presente, aunque esté lejos. (Entrevistada N. ${ }^{\circ}$ 10, 18 años)

Para esta última entrevistada, el tatuaje en común con sus hermanos reafirma la unidad familiar, los aspectos intersubjetivos de su identidad. El vínculo fraterno compone su subjetividad y a la vez se produce por la inminente separación ante los proyectos diferentes de cada uno.

2 Se entiende la subjetividad del otro como consustancial a la subjetividad propia. La intersubjetividad subraya que las subjetividades se constituyen a un tiempo en la relación (Paciuk, 2008). 
Otra lectura sobre esta experiencia de tatuaje en particular puede ser que los une en oposición simbólica ante sus padres, lo que recuerda el texto Tótem y tabú..., de Freud (1997a), con el mito del parricidio, que instituye la exogamia. El tatuarse la piel coincide en el tiempo con la partida a estudiar a otro país de uno de los hermanos y también con la finalización de la carrera universitaria de otra. En esta situación, el tatuaje podría adquirir el lugar simbólico del tótem. El tótem puede ser un antepasado común, un espíritu protector. Los individuos que poseen el mismo tótem tienen las mismas obligaciones y los mismos castigos, pueden vivir separados y están sujetos a la prohibición del incesto, otro contenido fundamental para generar cultura.

\section{MIRADA}

En la construcción del psiquismo, en las etapas tempranas se ponen en juego numerosas variables, situaciones, pulsiones; entre ellas, el par antitético propuesto por Freud en Los instintos y sus destinos (1997b) ${ }^{3}$ del exhibicionismo y la escoptofilia. En las etapas posteriores se continúa la búsqueda de ser mirado y de mirar. El tatuaje proporcionaría una forma de satisfacción a la pulsión de mirar y, a la vez, a la de ser mirados. Una de las características del tatuaje más valoradas por las personas tatuadas es la de su permanencia, quedar para siempre en la piel, lo cual podría estar ligado a la fantasía de eternizar el placer de ser mirados.

El tatuaje mueve la mirada del otro y la mirada del otro incide en el individuo tatuado. La mirada de un tatuaje ubicado en una zona que se puede ver solamente en la desnudez o en la intimidad tiene un sentido

3 La editorial Biblioteca Nueva traduce la obra como Los instintos y sus destinos, diferente a como lo hace la editorial Amorrortu, que traduce Las pulsiones y sus destinos. 
diferente para quien muestra y para quien mira. También para quien tiene un tatuaje en el cuello, por ejemplo, que ocupa visiblemente varios centímetros de piel, el sentido es distinto del que tiene para quien mira, que adopta una posición activa, frente al que es mirado, que queda en una posición pasiva. Pero este par antitético placer visual (escoptofilia) exhibicionismo, propuesto por Freud (1997b), no funciona linealmente, sino que tiene también destino hacia la propia persona. Es decir, la exhibición está dirigida hacia la contemplación del propio cuerpo. «Aparte, no me miran disimuladamente, me miran el cuello...» (Entrevistada N. ${ }^{\circ}$ 11, 20 años).

En la construcción del psiquismo, las etapas tempranas ponen en movimiento el par pulsional de mirar y mostrarse, mostrarse a otro sujeto para ser mirado y luego mirar, como el juego infantil de descubrimiento al mirar un objeto que no es propio.

... me gusta verlos y observarlos [...] me encantaría creer que al otro que lo mira le gusta [...] estoy tan segura de que me encantan a mí, que me da lo mismo lo que los demás digan. (Entrevistada N. ${ }^{\circ}$ 5, 23 años)

Cuando me miran los tatuajes me genera curiosidad saber que si les gusta... (Entrevistada N. ${ }^{\circ}$ 7, 24 años)

Se puede inferir que en el tatuaje se juega la primacía de ser mirado, ser contemplado, y del placer de mostrar. Pero, si profundizamos, encontramos la autocontemplación, el autoerotismo: «Acá sí me encanta que se vea, además tengo un lomazo...» (Entrevistada N. ${ }^{\circ}$ 1, 25 años). 


\section{SIGNIFICACIONES}

De la percepción del significado del tatuaje se puede inferir que queda vinculado a:

Los aspectos afectivos con las imagos primarias.

El proceso histórico que transitan.

El aporte en la construcción de la identidad.

Para algunas de las personas tatuadas, el tatuaje habilita la fantasía de reconstrucción de un yo jaqueado, como si a través de la marca en el cuerpo se tomara posesión de este. Es decir que, mediante la generación de un cambio en la presentación de la piel, el tatuado/a experimentaría un hito significativo para el pasaje a otra etapa de su vida.

Las/os jóvenes en su proceso de búsqueda de sí van construyendo aspectos de su subjetividad a través del tatuaje. Es una manera de autoafirmarse, de expresar los cambios en sus emociones, en sus proyectos y frustraciones. Mediante el tatuaje de fechas, imágenes o frases que remitan a ideologías, van construyendo su identidad, dándole sentido y dirección a sus vidas. Por ejemplo, en algunos casos, el tatuaje ayuda a mediar en situaciones emocionales dolorosas y complicadas, como el desarraigo o el inicio de la adultez.

Para otras personas, el tatuaje requiere de cierta negociación intergeneracional entre el deseo propio y las exigencias en los ámbitos laborales o familiares. La situación les exige pensar antes de actuar, darle un sentido al tatuaje y una ubicación en el cuerpo para evitar conflictos innecesarios con el entorno. Esta situación las habilita a pensar y, tal vez, a procesar sentimientos, actitudes, empatías, etcétera, de manera tal que les permita adaptarse mediando con el entorno, una expresión más acerca de la manera en que el individuo busca adaptarse en el proceso cultural actual. 
... estoy así y no me ves ningún tatuaje, si me pongo una camisa tampoco, y es algo que todavía he tratado de cuidar mucho, sobre todo por el mundo laboral y empresarial, todas esas cosas de estigmas que todavía existe... (Entrevistado N. ${ }^{\circ}$ 9, 24 años)

\section{DOLOR}

La exposición a un dolor mayor, ya sea para corregir o para hacer un tatuaje de tamaño más extenso, lleva a preguntar: ¿por qué se expondrían a ese dolor mayor? Desde Winnicott (1940) y Anzieu (1987) se podría pensar en el concepto de falla temprana, de manera tal que el individuo, por haber quedado atrapado en una envoltura de angustia, revive algo de lo angustiante en lo doloroso de tatuar sobre lo tatuado o de realizar tatuajes de gran tamaño y tolerar un gran dolor ya conocido varias veces.

Otra manera de pensarlo es como si fuera una adicción, de modo que el tatuaje provee de placer-dolor al individuo tatuado, quien no puede abandonar la práctica, pese a reconocer el sufrimiento que le proporciona. Sería, en ese caso, un mecanismo repetitivo, de acumulación de tatuajes, que no parecen propiciar cambios internos. Lo planteado por Reisfeld (2004) sobre conceptuar al tatuaje como operador psíquico que acompaña el proceso de simbolización no sería posible en estos casos.

El tatuaje siempre constituye una agresión al órgano piel. La función biológica y psíquica de la piel queda alterada. El tatuaje puede producir reacciones alérgicas por las tintas, puede haber infecciones por negligencia al momento de tatuarse o cuidarse el tatuaje; también, los metales pesados de las tintas pueden alojarse en los ganglios y comprometer gravemente la salud. Se podría entender, de alguna manera, a estas autoagresiones como embates agresivos del inconsciente, que se apuntalarían en fenómenos orgánicos. Aquí cobra sentido lo que Anzieu (1987) propone sobre la 
piel, como piel imaginaria que recubre al yo. Luego de la realización del tatuaje, la piel alteraría sus funciones biológicas y se convertiría para el yo en una túnica envenenada, como función tóxica del Yo-piel.

\section{CONCLUSIONES}

Se han visto una multiplicidad de sentidos acerca de cómo pensar el tatuaje y su relación con el psiquismo de las/os jóvenes. Entre dichos significados se destacan los siguientes:

El tatuaje concretiza lo vivido y lo mantiene presente. La piel es como un lienzo que porta su historia. En situaciones de fragilidad yoica, el tatuaje fortalecería al yo. Le provee al tatuado/a valoración y autoestima, porque a través del tatuaje se apropia de su cuerpo y forma parte de su nueva identidad.

La moda del tatuaje puede ser entendida como consumo que vacía de sentido al individuo y a la vez lo hace parte de la masificación. Individualiza a quien porta el tatuaje por el contenido particular de la imagen, frase o fecha tatuada. Asimismo, forma parte de la masificación de los tatuados, que se diferencian de los no tatuados. Pero, además, se distinguen dentro de los tatuados, conformando subgrupos por afinidad de estilos de tatuajes.

El tatuaje aporta a la construcción de la subjetividad de la tatuada/o a través de la incidencia del grupo de pares, lo que provee identidad, contención y pertenencia.

Tatuarse contribuye a la tramitación de aspectos del duelo o de procesos que acompañan la simbolización, en tanto operador psíquico (Reisfeld, 2004). Se construye una nueva cadena de significaciones a partir de realizarse el tatuaje y, sobre todo, con el transcurso del tiempo. Ante situaciones dolorosas o complicadas que viven los/as 
jóvenes, el tatuaje aparece en relación tanto a la posibilidad de elaboración de duelos, como también a la situación contraria de negación. Para la mayoría de las personas tatuadas, el par antitético de ser mirado y mirar queda eternizado a través del tatuaje. Para otras, el tatuaje aparece como una marca que no estaba en el cuerpo y podría producir extrañeza; podría expresar lo ominoso e implica la necesidad inminente de sacarlo o taparlo ante la angustia desbordante.

\section{POSIBLES TEMAS A INVESTIGAR}

Uno de los aspectos más importante de la investigación fue la inmensa riqueza de cada entrevista. Se podría generar una investigación particular con cada una de ellas. El malestar en la cultura de principios del siglo Xxi se manifiesta de muy diversas maneras: a través de las necesidades económicas, del sometimiento a las normas culturales y del repudio a dichas normas, de la sexualidad siempre cuestionada, de la agresividad a flor de piel cuando el tatuaje se pone de moda y se vacía de sentido, pero siempre en búsqueda de un espacio, de una identidad o del amor.

Si bien no se entrevistó a quienes se quitan los tatuajes, se realizó una exploración en las páginas web de las clínicas en Montevideo dedicadas al tratamiento con láser para remover tatuajes. Podría este convertirse en un tema de investigación, que implicaría aspectos tales como la impulsividad, la negación, la renegación, lo ominoso (lo siniestro) (Freud, 1994a). ¿Qué sucede cuando el tatuaje expresa algo de lo sabido no pensado (Bollas, 2009)?

¿Cuánto del cambio en los sentidos sociales del tatuaje inciden en el efecto psíquico que producen? Resulta interesante pensar e investigar sobre los posibles sentidos culturales que va adquiriendo el tatuaje, como moda, identidad, expresión artística, simbología de la imagen tatuada. 
Una característica peculiar de la muestra fue la manera en que se conformó, ya que las personas entrevistadas fueron en su mayoría mujeres. Estas se mostraron con una mayor disposición a participar y a expresarse sobre sus tatuajes. Este aspecto es importante para pensar desde lo cultural las identidades de género y las diferencias sexuales.

Otro tema inesperado que surgió durante las entrevistas fue la presencia e importancia de los abuelos/as, registrada en los tatuajes de las/ os entrevistadas/os. Se trata de una generación que estableció vínculos intergeneracionales sorprendentes ante la ausencia de padre o madre.

Otra posible interrogante tiene que ver con lo erótico en el vínculo entre tatuado/a y tatuador/a. ¿Qué promueve el vínculo que se construye entre ellos/as cuando el tatuaje a realizarse requiere de varias sesiones? Esta particular situación suele ejecutarse en un entorno privado, en largas sesiones en las que el acceso al cuerpo a través del tacto, la mirada y el dolor promueve un vínculo de seducción y erotismo, donde también se juegan los diferentes roles, los aspectos afectivos, las carencias. Los aspectos que puedan desplegarse en el vínculo entre tatuador/a y tatuado/a ameritarían un abordaje específico.

\section{REFERENCIAS BIBLIOGRÁFICAS}

Allouch, J. (1996). Erótica del duelo en el tiempo de la muerte seca. Edelp. Anzieu, D. (1987). El Yo- piel. Biblioteca Nueva.

Bollas, C. (2009). La sombra del objeto. Psicoanálisis de lo sabido no pensado. Amorrortu. 
FREUd, S. (1994a). Lo ominoso (1919). En Obras completas (vol. XVII, pp. 215-252). Amorrortu.

FREUd, S. (1994b). El malestar en la cultura (1930). En Obras completas (vol. xxI, pp. 57-140). Amorrortu.

FREUd, S. (1997a). Tótem y tabú. Algunas concordancias en la vida anímica de los salvajes y de los neuróticos (1913 [1912-13]). En Obras completas (vol. v. pp. 1745-1758). Biblioteca Nueva.

FREUd, S. (1997b). Los instintos y sus destinos. Obras completas (vol. vi, pp. 2039-2052). Biblioteca Nueva.

FREUd, S. (1997c). Duelo y melancolía. En Obras completas (vol. vI, pp. 2092-2100). Biblioteca Nueva.

Lipovetsky, G. (2006). La era del vacío. Ensayos sobre el individualismo contemporáneo. Anagrama.

McLuhan, M. y Powers, B. (1995). La aldea global. Transformación en la vida y medios de comunicación mundiales en el siglo XXI. Gedisa.

Paciuk, S. (2008). De intrapsíquico a intersubjetivo. Revista Uruguaya de Psicoanálisis, 107, 137-153. www.apuruguay.org/apurevista/2000/ 16887247200810715.pdf

Piaget, J. (1991). Seis estudios de psicología. Labor.

ReISFeLD, S. (2004). Tatuajes: una mirada psicoanalítica. Paidós.

WinnicotT, D. (1940). Los bebés y sus madres. Paidós.

WinNicotT, D. (1965). Los procesos de maduración y el ambiente facilitador. Paidós. 
